\title{
Coğrafi Bilgi Sistemleri Kullanılarak Su Havzalarındaki Doğal Kaynakların İzlenmesi: EImalı Havzası Örneği
}

\author{
Abdurrahman GEYMEN* \\ Erciyes Üniversitesi, Mühendislik Fakültesi Harita Mühendisliği Bölümü, Kayseri
}

Geliş (Received): 24.02.2016

Kabul (Accepted): 09.04.2016

\begin{abstract}
ÖZET: İstanbul, Türkiye'nin en kalabalık şehri olup özellikle son 20 yıl içerisinde büyük göçler nedeniyle nüfus hızla artmıştır. Hızlı, denetimsiz ve illegal kentleşme, su havzaları içerisinde ormanlar, yeşil alanlar ve tarım alanlarının tahribine sebep olmuştur. TEM otobanı ve Boğaziçi Köprüsü, arazi kullanım değişimini hızlandırmış, bu alan içerisinde kalan su havzalarını negatif yönde etkilemiştir. İstanbul'un en büyük su ihtiyacını karşılayan ve arazi kullanım değişiminden negatif yönde etkilenen su havzalarından birisi olan Elmalı havzası çalışma alanı olarak seçilmiştir. Bu çalışmada, Elmalı havzasındaki arazi kullanım değişiminin zamana bağlı olarak değişimi, 1995, 2005 ve 2013 yıllarına ait Landsat uydu görüntüleri kullanılarak gerçekleştirilmiştir. Uydu görüntüleri Erdas Imagine 9.1 yazılımında değerlendirilerek elde edilen sonuçlar Coğrafi Bilgi Sistemine aktarılmıştır. Su havzalarındaki mevcut planların uygulanamaması nedeniyle arazi kullanımında değişimler olduğu ve doğal kaynakların hızla azaldığı sonucuna ulaşıııışıı. Çalışmada ayrıca su havzalarındaki doğal kaynakların bu derece hızla azalmasına sebep olan unsurlar da tartışılmıştır.
\end{abstract}

Anahtar Kelimeler: Uzaktan Algılama, Coğrafi Bilgi Sistemleri, Su havzaları.

\section{Monitoring of Natural Resources in Water Basin Using Geographical Information Systems: Elmalı Basin Case Study}

ABSTRACT: Istanbul is the most populated city of Turkey and the population was increased in especially last two decades due mainly to the large immigrations. The rapid, uncontrolled, and illegal urbanization caused degradation of forested, crop and grass lands in the Elmalı water basin. The transportation networks accelerated the land-use changes, which have negative impacts on water basins in the metropolitan area. The Elmalı which is one of the largest water basins of Istanbul providing drinking water and negatively affected by the land-use changes, was selected as study area. In this study, the time dependent land-use changes in Elmalı water basin was carried out by using Landsat ETM satellite images in 1995, 2005 and 2013. The image processing data were transferred to Geographic Information Systems. According to the results the study, failure on implementing the existing plans for the water basin was resulted in the land-use changes and the rapid decrease of natural resources. The factors contributing to the rapid decrease of natural resources in Elmalı Basin were also discussed.

Key Words: Remote Sensing, Geographical Information System, Water basins

\section{GİRIS}

Dünya nüfusundaki hızlı artış ve ulusal sermayenin tarım merkezli sistemlerden uzaklaşması kentlerin daha hızla büyümesine neden olmuştur. Yerel yönetimler tarafindan kentsel gelişmenin izlenememesi nedeniyle su havzaları içerisindeki orman ve tarım alanları gibi doğal kaynaklar azalarak organize sanayi bölgelerine ve yerleşim alanlarına dönüş̧ürülmüştür. $\mathrm{Bu}$ kontrol edilemeyen dönüşüm hatalı arazi kullanımları olarak karşımıza çıkmaktadır (Gülersoy, 2001; Gülersoy, 2008; Topaloğlu ve Ekercin, 2013). Aynı zamanda hızlı ve plansız kentleşme, ormanlık alanlarının azalmasına, su ve diğer doğal kaynakların kirletilmesi gibi birçok çevresel etkilere sebep olmaktadır (Yıldırım ve Kılıç, 2006; Yılmaz ve ark., 2015). Doğal kaynaklar üzerindeki bu baskılar sonucu oluşan çevresel problemlerin giderilmesi için, kentin izlenebilir ve sağlıklı bir şekilde sürdürülebilir gelişmesi sağlanmalıdır. Sürdürülebilirlik, kentteki yaşam kalitesinin artırılması ile kenti besleyen ve kentin yaşam kaynağı olan doğal kaynakların korunmasını esas almaktadır. Kentleşme olarak dünya ortalamasının üzerinde olan ülkemizde, gelecekte daha planlı ve sürdürülebilir şehirler elde etmek için teknolojik yöntemler kullanılarak kentleşmenin izlenmesini ve planlamaların bu duruma göre yapılmasını zorunlu kılmaktadır (Geymen ve ark., 2005; Kaya ve Toroğlu, 2015).

$\mathrm{Su}$ havzalarındaki arazi kullanım değişiminin izlenmesi, ekonomik, sosyal, politik ve ekolojik şartların bir fonksiyonudur (Kaya ve Toroğlu, 2005). Bu alanlardaki arazi kullanım değişimi yönüyle ilgili olarak elde edilecek veriler, gelecekteki nüfus artı̧̧ gibi bir takım projeksiyonların belirlenmesi açısından son derece önemlidir (Öztürk ve ark., 2010). Arazi kullanımı ile ilgili istatistikler, halihazır haritalar ve tematik haritalar gibi grafik veriler çoğu kez topografyanın son halini göstermemektedir. Topografyanın güncel haritası için ihtiyaç duyulan bu verilerin arazi çalışmalarından veya hava fotoğraflarından elde edilmesi ise oldukça masraflı ve zaman alıcıdır. Uydu görüntüleri geniş alanları kapsaması, farklı tarihlere ait görüntülerin mevcut olması, elektromanyetik spektrumun farklı bölgelerinde 
algilama yapılabilmesi ve ekonomik olması nedeniyle önemli bir veri kaynağı olarak yaygın bir şekilde kullanılmaktadır (Öztürk ve ark., 2010).

Hızlı ve plansız kentleşmenin oluşumunu engellemek, kentsel gelişimi gelişen teknolojilerden yararlanarak planlamak ve izlemek, doğal kaynakları koruyacak ve dengede tutacak arazi kullanım politikaları geliştirmek, planlamalarda geleceğe yönelik ihtiyaçlarında göz önüne alındığı alanların dengeli bir dağılımını sağlamak için arazi kullanımının güncel durumuna ve geçmişteki doğal yapısı hakkındaki bilgilere ihtiyaç duyulmaktadır (Canıberk ve Kiracı, 2014). Uydulardan elde edilen görüntülerde ve bilişism teknolojisindeki hızlı gelişmeler, Uzaktan Algılama ve Coğrafi Bilgi Sistemlerinin (CBS) gelişmesine etki etmiştir (Kaya ve Toroğlu, 2015). Bu sistemlerin hızlı ve güvenir olması dünyada ve ülkemizde Uzaktan Algılama ve CBS teknikleri kullanılarak su havzalarında arazi kullanım değişimleriyle ilgili ayrıntılı çalışmalar yapılmasına neden olmuștur (Wu ve ark., 2005; Shalaby ve Tateishi, 2007; Dewan ve Yamaguchi, 2009; Gürbüz ve ark., 2012; Kara ve Karatepe, 2012; Akbulak, ve ark., 2008). Bu çalışmaların genelinde elde edilen sonuç arazi kullanımında doğal kaynaklarda meydana gelen değişimler olduğu ve bu değişimin en önemli sebebinin yerel yönetimlerin uygulamada plan kararlarını doğru uygulanamadığıdır (Gülersoy, 2010). Uzaktan Algılama ve CBS tekniklerinin hızlı ve güvenilir sonuçlar vermesi, karar verme süreçlerinde ve planlamada bu tekniklerinin kullanılmasını yaygınlaştırmıştır (Liu, 2009).

Bu çalışmada, Uzaktan Algılama ve Coğrafi Bilgi Sistemleri (CBS) teknikleri kullanılarak, Landsat ETM $(1995,2005,2013)$ uydu görüntülerinden yararlanılarak, İstanbul Metropolitan alan içerisindeki, İstanbul'un su teminini sağlayan en büyük havzalardan birisi olan Elmalı havzasının arazi kullanım değişikliği incelenmiştir. Bu amaçla arazi kullanımına ait 6 farklı arazi kullanım kategorisi belirlenmiştir. $\mathrm{Bu}$ arazi kullanım kategorilerinin yıllara göre değişimleri, CBS teknikleri içerisindeki konumsal analizler yapılmak suretiyle elde edilmiştir.

\section{MATERYAL ve METOT}

İstanbul'un su ihtiyacını karşılayan en büyük havzalardan biri olan Elmalı havzasında meydana gelen arazi kullanım değişiminin tespit edilebilmesinde yönelik izlenen işlem adımları Şekil 1'de gösterilmiştir.

\section{Çalışma Alanı}

Elmalı Havzası, İstanbul'a içme suyu temin eden havzalardan biri olup çalışma alanı olarak seçilmiştir (Şekil 2). Elmalı havzası Asya yakasında olup İstanbul'un şehir merkezine yaklaşı $15 \mathrm{~km}$ uzaklıkta yer almaktadır. Havza, İstanbul Su ve Kanalizasyon İdaresi İçme Suyu Havza Yönetmeliği'ne göre koruma bantlarına ayrılmıştır. Elmalı havzasının batı bölümünde
İkinci Boğaz Köprüsü ve güney bölümünde ise TEM otoyolu geçmekte olup havzanın mevcut arazi kullanımı yapısının şekillenmesinde önemli bir rol oynamıştır (Balçık ve ark. 2005). Son yirmi yılda hızlı kentleşme havza içerisindeki doğal yapının bozulmasına en büyük etkinin ulaşım ağı ve havzanın şehir merkezine olan yakınlığı olarak tespit edilmiştir (Musaoğlu ve ark. 2005).

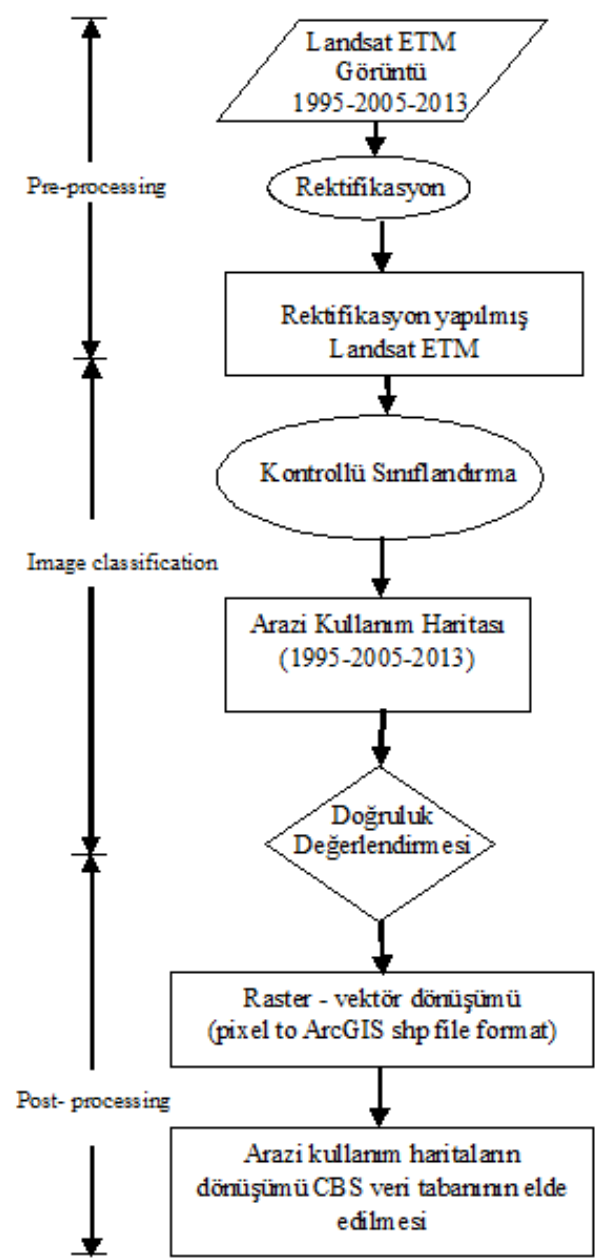

Şekil 1. Çalışmada izlenen yöntem

\section{Veri Setleri}

Çalışmada su havzalarında belirlenen arazi kullanım desenlerini tespit etmek için 1995, 2005 ve 2013 yılları Haziran ayına ait Landsat ETM (Path/Row: 180/31) uydu görüntüleri kullanılmıştır. Bu uydu görüntülerinin konumsal çözünürlüğü 30 metredir. Aynı zamanda bu haritalara altlık olması bakımından Ikonos uydu görüntüleri, 1:25000 ölçekli topografik haritalar ve 1:100000 ölçekli çevre düzeni planlarından yararlanılmıştır. Uydu görüntüleri URL, (2016) sitesinden temin edilmiştir. 


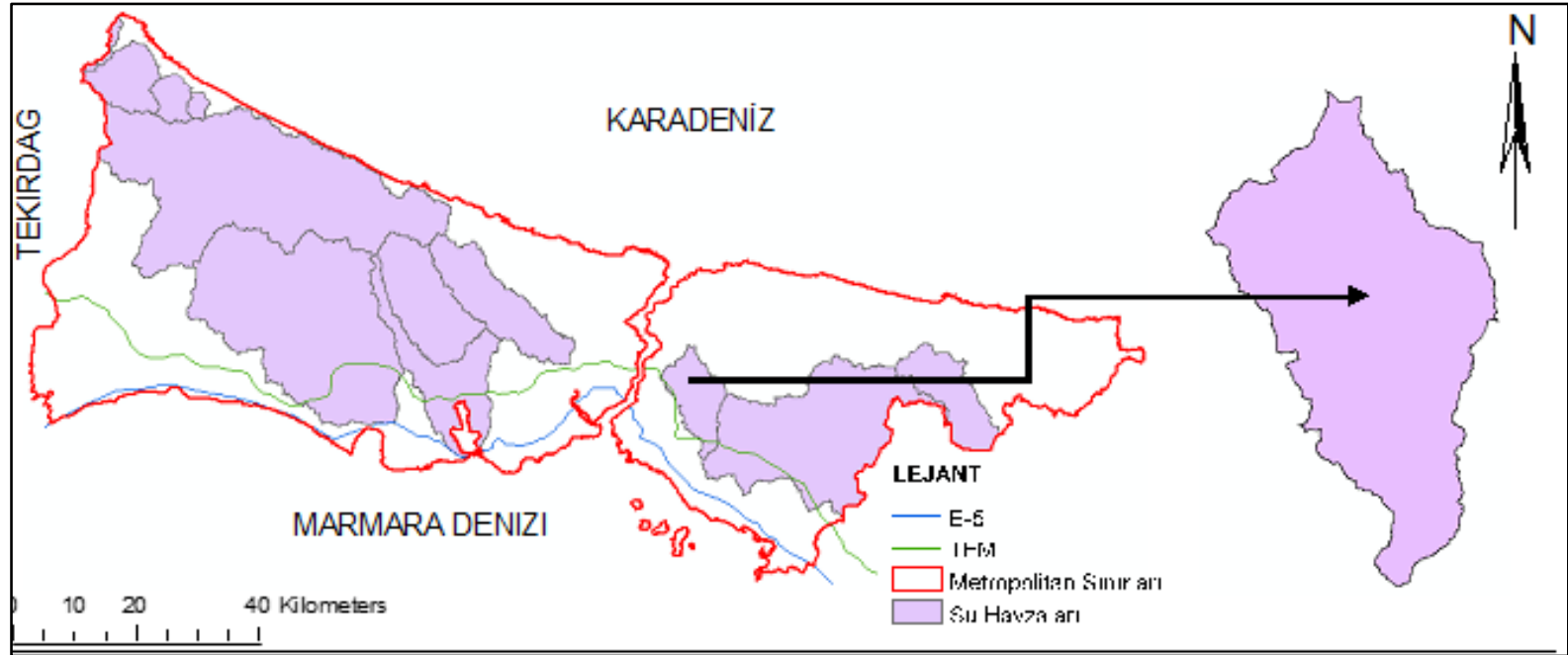

Şekil 2. Çalışma alanı

\section{Görüntü Ön İșleme}

Görüntülerde atmosferik parçacıklardan dolayı meydana gelen etkileri en aza indirmek için Landsat ETM uydu görüntülerine radyometrik ve atmosferik düzeltme uygulanmaktadır (Liang, 2004). Çalışma alanında arazi kullanım değişikliği için temin edilen Landsat uydu görüntülerinde bu düzeltmeler giderilmiş olarak elde edilmiştir. Uzaktan Algılama görüntülerinde oluşan sistematik ve sistematik olmayan hataların giderilmesi için geometrik düzeltme uygulanmıştır. Analiz işlemi sırasında referans veri olarak 1995 yılı görüntüsü için 1995 yılı 1:5000 ölçekli hava fotoğrafları ve aynı görüntünün 3,2,1 bantlı kombinasyonlu görüntüsü, 2005 ve 2013 yılı görüntüleri için aynı yıllara ait Ikonos uydu görüntüsü kullanılmıștır. 1995 Landsat görüntüsünde 29 kontrol noktası seçilmiştir. Karesel Ortalama Hatası 0.59 pixel'dir. 2005 Landsat görüntüsünde 36 kontrol noktası seçilmiştir. Karesel Ortalama Hatası 0.52 pixel'dir. 2013 Landsat görüntüsünde 44 kontrol noktası seçilmiştir. Karesel Ortalama Hatası 0.49 pixel'dir.

\section{Görüntï Sinıflandırma}

Bir görüntüdeki her bir piksel değerinin sahip olduğu özellik grubunun belirlenmesi ve seçilen bantlar için benzer spektral özelliklere sahip piksellerin özellik gruplarına atanması işlemi sınıflandırma olarak tanımlanmaktadır (Gürbüz ve ark., 2012; Balçık ve ark., 2011). Bu amaçla Landsat uydu görüntülerinde ilk önce kontrollü sınıflandırma işlemi yapılmıştır. Örnek bölgelerin toplanması sırasında örnekleme alımını kolaylaştırmak, bantlar arası korelasyonu azaltmak için "Temel Bileșenler Analizi" uygulanmış ve önceden belirlenen altı sınıfa ait örnekleme bölgeleri toplanması işlemine geçilmiştir. Örnekleme bölgeleri seçiminde altlık olarak hava fotoğrafları ve Ikonos uydu görüntülerinden yararlanılmıştır. Erdas 9.1 yazılımında, aynı koordinat sisteminde olan uydu görüntüsü ile altlık olarak kullanılan Ikonos görüntüsü 2 farklı pencerede açlarak görüntüler arasında link kurulmuștur. Bu link ișlemi örnekleme bölgelerinin arazi kullanım türlerinin belirlenmesinde kolaylık sağlamıştır. Yeterli sayıda örnekleme toplandıktan sonra "En Yüksek Olasılık" kontrollü sinıflandırma yöntemi uygulanmıştır. Sınıflandırma işlemlerinin tüm aşamalarında Erdas Imagine 9.1 yazılımı kullanılmıştır. Kontrollü sınıflandırma işleminden sonra görsel değerlendirmeyi arttrrabilmek amacıyla 3x3'lik Median Filtreleme uygulanmıştır.

\section{Doğruluk Analizi}

Sınıflandırma işlemi bitirildikten sonra yapılan işlemlerin doğruluğunu tespit etmek amaciyla sınıflandırılan görüntüler için doğruluk analizi yapılmıştır. Analiz sırasında çalışma alanı büyüklüğü göz önüne alınarak 6 sınıf için toplam adet 200 kontrol noktası rasgele üretilmiştir. Cizelge 1'de görüldüğü üzere bu 200 noktanın her biri sinıflandırılan görüntü ve referans veriler üzerinde karşılaştırılarak çalışmanın genel doğruluğu tespit edilmiştir. Genel doğruluğun yanında sınıflandırma doğruluğu için kullanılan diğer bir ölçüt olan Kappa $(\kappa)$ katsayı hesaplanmıştır. Kullanılan her bir uydu görüntülerinden elde edilen genel doğruluk ve kappa doğrulukları Çizelge 1'de verilmiştir. Genellike $\kappa$ deperinin \%80'in üzerindeki değerleri iyi bir sınıflandırmayı gösterirken \%40'ın altı ise kötü bir sınıflandırmaya karşılık gelir (Congalton, 1991; Congalton, 1998).

Çizelge 1. Elmalı havzası için sınıflandırma doğruluğu sonuçları

\begin{tabular}{lcc}
\hline Uydu Görüntüleri & $\begin{array}{c}\text { Genel doğruluk } \\
(\%)\end{array}$ & $\begin{array}{c}\text { Kappa } \\
(\%)\end{array}$ \\
\hline 1995 Landsat ETM & 89 & 82 \\
2005 Landsat ETM & 86 & 83 \\
2013 Landsat ETM & 91 & 86 \\
\hline
\end{tabular}

\section{CBS veritabanının olusturulması}

Erdas Imagine 9.1 yazılımı kullanılarak Uzaktan Algılama görüntüleri sınıflandırılmıştır. Sınıflandırılan bu görüntüleri ArcGIS 10.3 yazılımında "Raster to Polygon" ArcToolbox komutu ile vektör veri modeline dönüştürülmüştür. $\mathrm{Bu}$ veri modeline dönüşüm işlemindeki 
amaç katmana ait sorgulama ve analiz işlemlerinin gerçekleştirilebilmesi içindir. Daha sonra vektör veriye dönüştürülmüş katman "Clip" ArcToolbox komutuyla Elmalı havza sınırından kesilerek arazi kullanım haritas elde edilmiştir. Elde edilen bu arazi kullanım haritası geodatabase (gdb) formatında saklanarak CBS veritabanı oluşturulmuştur. Geodatabase dosya formatının avantajı grafik verilerdeki topolojik hataları otomatik olarak giderebilmesidir.

\section{BULGULAR}

CBS veritabanı üzerinde sınıflandırılmıș görüntülerden elde edilen arazi kullanım haritalarına ait değişim değerleri tablosu Çizelge 2'de gösterilmiştir. Çizelge 2'de tespit edilen arazi kullanım sınıflarındaki tanımlamalar için Anderson ve ark. (1976) yılında Landsat GeoCover uydu görüntüleri için yapmış olduğu tanımlamalardan yararlanılmıştır. Tespit edilen 6 sınıftan çalılık alanlar; ormanların tahribi ile meydana gelen küçük ağaç guruplarının oluşturduğu bitki formasyonunu, su alanları; havzayı oluşturan su kütlelerinin oluşturduğu alanı, yerleşim alanları; havza içerisinde birtakım amaçlarla yapılmış yapı alanlarını, ormanlık alanlar; yaprağını döken/dökmeyen ağaç yapılarını, çorak toprak; tarıma elverişsiz verimsiz ve boş arazileri, tarım alanları ise üzerinde ekim yapılan alanları göstermektedir.

Çizelge 2. Sınıflandırılmış görüntülerden elde edilen arazi yüzeyleri değișim değerleri tablosu

\begin{tabular}{lcccccc}
\hline \multirow{2}{*}{ Sinıf/Yil } & \multicolumn{2}{c}{1995} & \multicolumn{2}{c}{2005} & \multicolumn{2}{c}{2013} \\
\cline { 2 - 7 } & ha & $\%$ & ha & $\%$ & ha & $\%$ \\
\hline Çorak Toprak & 92 & 1 & 61 & 1 & 59 & 1 \\
Tarım & 423 & 5 & 117 & 1 & 84 & 1 \\
Orman & 4135 & 50 & 3778 & 45 & 3757 & 45 \\
Yerleşim & 2444 & 29 & 3233 & 39 & 3378 & 40 \\
Su & 97 & 1 & 72 & 1 & 72 & 1 \\
Çalılık & 1150 & 14 & 1080 & 13 & 991 & 12 \\
\hline Toplam & 8341 & 100 & 8341 & 100 & 8341 & 100 \\
\hline
\end{tabular}

Şekil 3, Şekil 4 ve Şekil 5, Çizelge 2'de gösterilen değişim değerleri tablosunun tematik harita olarak gösterimidir. Şekil 6 ise Elmalı havzasındaki yapılaşmanın yoğunluğunu görüntülemektedir. 1995-2013 yılları arasında toplam alana göre en fazla etkilenen alanların dağılımı göz önüne alındığında, yerleşim alanları \%29'dan \%40’a yükselmiş iken, tarım alanları $\% 5$ 'den $\% 1$ 'e, ormanlık alanlar ise \%50'den \%45'e düşmüştür. Havza içerisindeki yerleşim alanlarının artması, tarım ve ormanlık alanlardaki azalmalar 1995-2013 yılları arasında çalışma alanında hızlı ve plansız bir arazi kullanım değişimi olduğu gözlenmektedir.

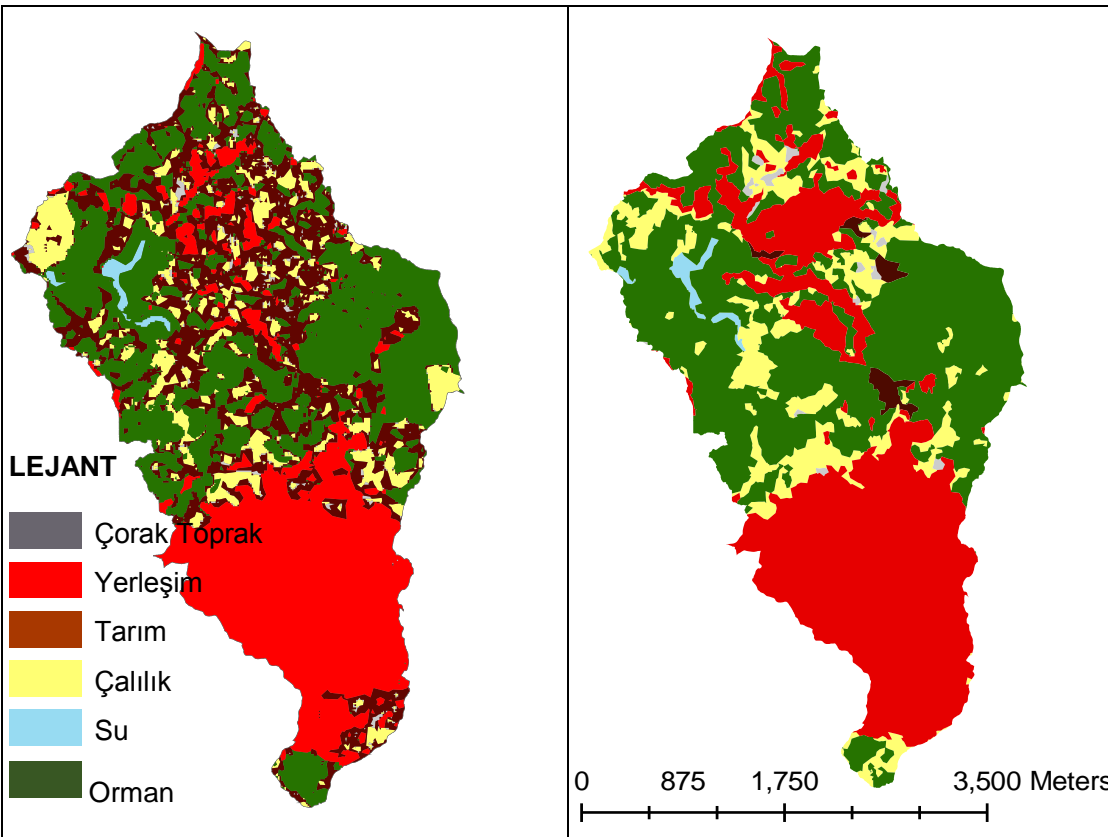

Şekil 3. 1995 yılı Elmalı havzası arazi kullanımı

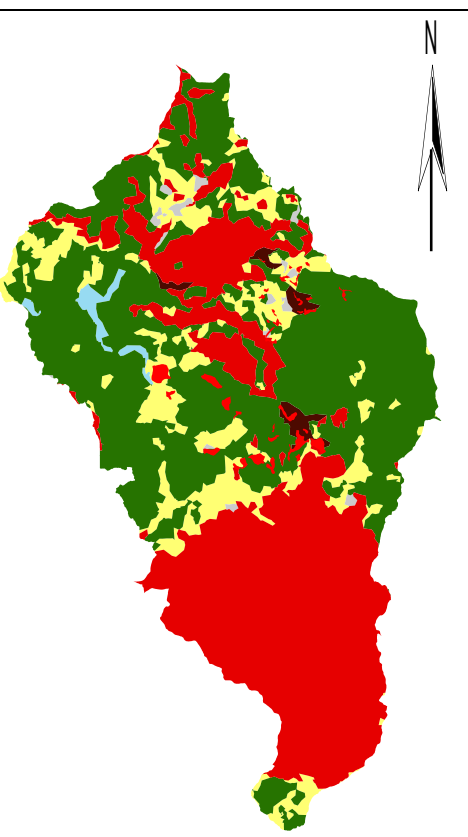

Sekil 5. 2013 yılı Elmalı havzası arazi kullanımı 

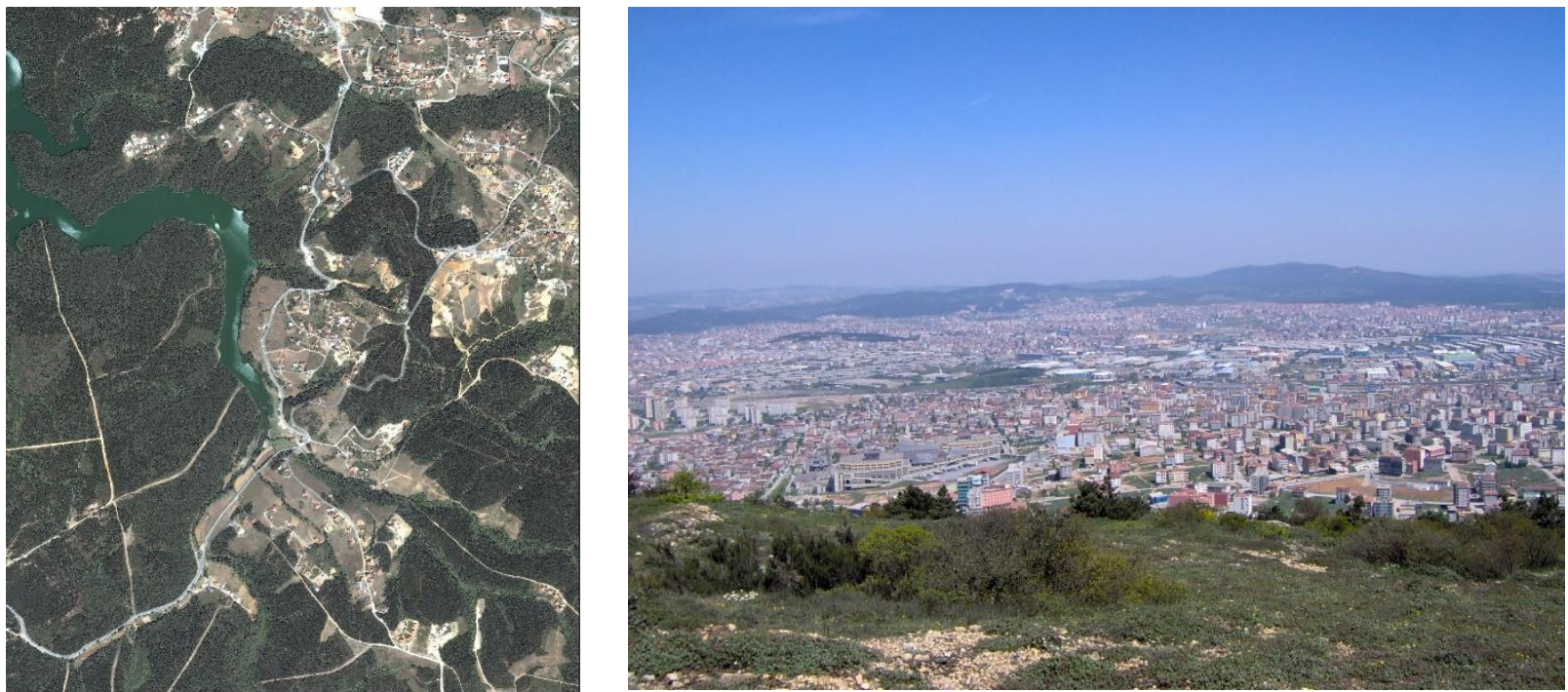

Şekil 6. Elmalı havzası yerleşim alanları

\section{TARTIŞMA} İlişki

Nüfus ve Arazi Kullanım Değişimi Arasındaki

Türkiye son 80 yıldan günümüze kadar olan süreç içerisinde endüstri ve tarım alanında hızlı bir değişime uğramıştır. Bu hızlı değişim beraberinde özellikle İstanbul, Ankara, İzmir, Adana gibi illere göçleri hızlandırmıştır (Geymen, 2013; TUİK, 2014). Bugün,
İstanbul metropol ölçeğinde dünyanın en büyük şehirlerinden birisidir. İstanbul'un 1950-2010 y1lları arasında büyüme oranı Şekil 7'de gösterilmiştir. Bu anlamda ne ilçe belediyeler nede Büyükşsehir belediyeleri göçleri kontrol altına alamamışlardır. Ormanlık alanlar, tarım alanları ve su havzaları kontrolsüz ve plansız yapılaşmaya maruz kalmışlardır.

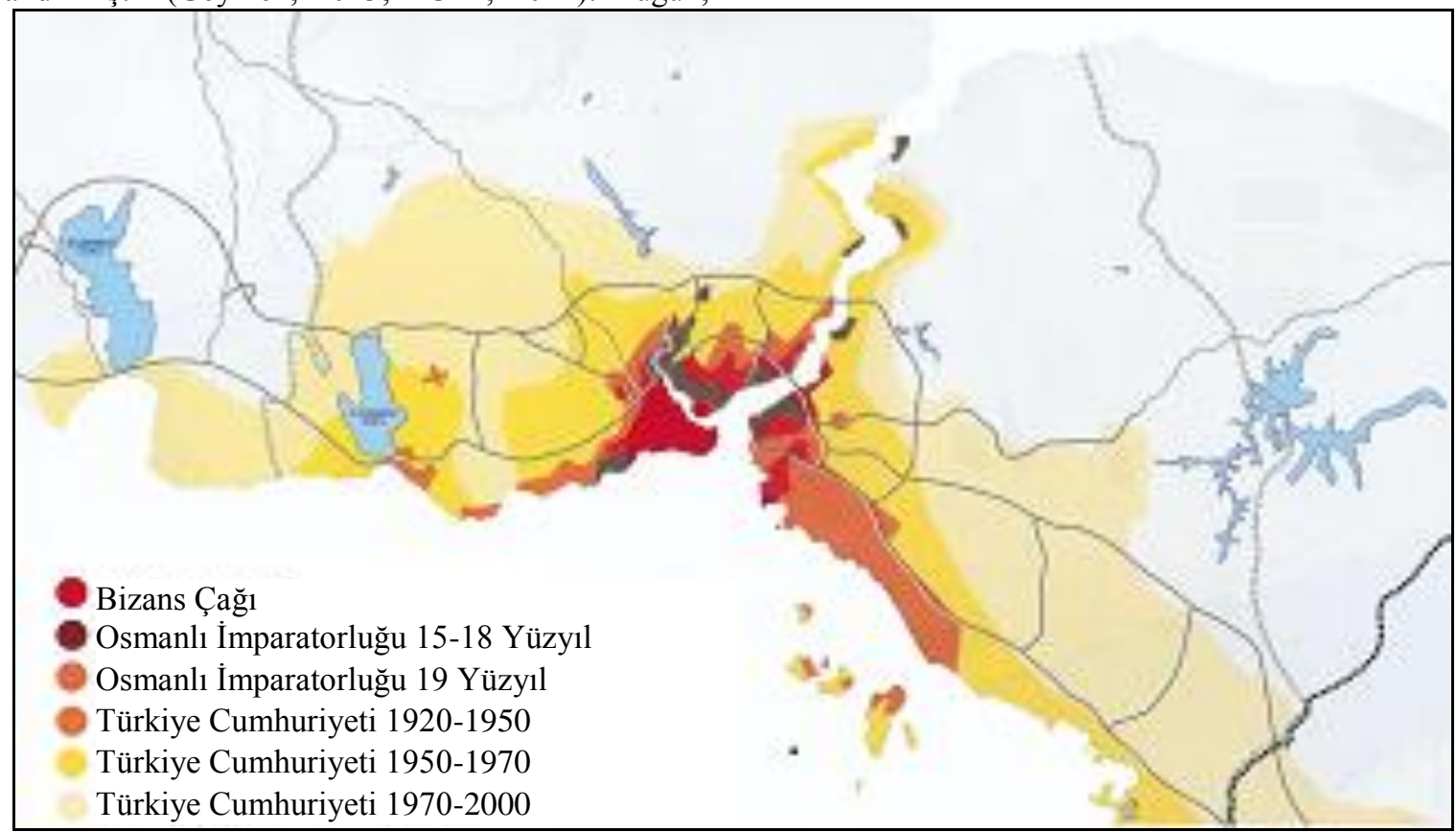

Şekil 7. İstanbul'un nüfus ile yerleşim alanları arasındaki ilişki ve büyüme oranı (IMP, 2006)

Çalışma alanı olarak seçilen Elmalı Havzası, Beykoz İlçesi Çavuşbaşı Bölgesi içerisinde bulunmaktadır. Bölge, 1980'li yıllardan itibaren yoğun biçimde göç almıştır. Meydana gelen plansız yapılaşmalar ciddi boyutlara ulaşınca Çavuşbaşı, Kültür Bakanlığı Kültür ve Tabiat Varlıklarını Koruma Kurulu Müdürlügünün 1995 tarihli kararı ile sit alanı ilan edilmiştir (KTVKK,
1995). Alınan önlemlere rağmen Çizelge 2'de de görüldüğü üzere Elmalı havzası kentleşmenin etkisi altında kalmıştır. Çizelge 2'deki değişim değerleri tablosunda 1995-2005 yılları arasında orman alanlar 357 ha, tarım alanları ise 306 ha azalırken yerleşim alanları 789 ha artmıştır. Bu değişim ormanlık ve tarım alanlarının \%84'ünün 2005 yılında yerleşim alanlarına 
dönüştüğünü göstermektedir. Çizelge 3'de verilen Türkiye İstatistik Kurumu (TUIK) verileri incelendiği zaman 1990-2000 yılları arasında Çavuşbaşı bölgesinin nüfusundaki \% 236 oranında ciddi derecede bir artışın olduğu görülmektedir. 2008 yılında Çavuşbaşı Beykoz Belediyesi'ne bağlanmıştır.

Çizelge 3. Çavuşbaşı'nın yıllara göre nüfus bilgileri (TUİK, 2014)

\begin{tabular}{ccc}
\hline Y1llar & Nüfus & \% Değişim \\
\hline 1965 & 1445 & \\
1970 & 1501 & 4 \\
1975 & 1981 & 32 \\
1985 & 2841 & 43 \\
1990 & 4693 & 65 \\
2000 & 15753 & 236 \\
2007 & 19539 & 24 \\
\hline
\end{tabular}

\section{Ulaşım Ă̆ı ile Arazi Kullanım Değişimi Arasındaki İlişki}

Şekil 1'de gösterildiği üzere TEM otoyolu Elmalı havza koruma alanlarının içinden geçmektedir. Şekil 3 5'de ise Elmalı havzasındaki arazi kullanım değişimi gösterilmektedir. TEM otoyolu, Elmalı havzasının güney yönünden geçerek oluşturduğu çekim etkisiyle, plansız yapılaşmayı artırarak doğal kaynakların zarar görmesine neden olmuştur. Geymen'in 2013 yılında yapmış olduğu çalışmasında çok büyük bir kısmı su toplama havzalarında kalan 3. Boğaz Köprüsü'nün bağlantı yollarının İstanbul'un önemli içme suyu rezervleri olan Ömerli, Elmalı, Darlık, Alibeyköy, Büyükçekmece, Sazlıdere ve Terkos havzalarından geçtiğini ve bu durumun su havzalarını yoğun yapılaşma baskısı altında bırakacağını tespit etmiştir. Şekil 7'de gösterildiği üzere Boğaziçi, Fatih Sultan Mehmet ve 3. Köprünün inşası, İstanbul'un kuzeyinde doğal kaynakların en yoğun bulunduğu alanlara doğru kentsel alanların büyümesine neden olmuştur. Bölgede sadece TEM otoyolu değil aynı zamanda sanayi yatırımları da doğal kaynaklara negatif etki yapmıştır. Dudullu Organize Sanayi Bölgesi, havzanın güney kısmında tesis edilmiştir. Bu yatırımlar, Dudullu ve Çekmeköy'de devlet arazileri üzerinde kaçak yapıların oluşmasına sebep olmuştur. Sonuçta, su havzaları, otoyol, organize sanayi ve yoğun yerleşim alanlarından oluşan bir kirlilik meydana gelmiştir.

\section{İSKİ İcme Suyu Havzaları Yönetmeliğinin Arazi} Kullanım Değişimine Etkisi

İSKİ'nin İstanbul'daki su havzaları için çıkartmış olduğu içme suyu havzalar yönetmeliği 1984 yılında yürürlüğe girmiş olup bu yönetmelikte 1994 yılında bazı değişikliğe gidilmiştir. 1984 ve 1994 tarihlerindeki yönetmeliğin temeli ise havzalardaki yapılaşmanın düzenlenmesi amacı ile 1976 yılında Sağlık Bakanlığı, İmar ve İskân Bakanlığı ve Devlet Su İşleri Genel Müdürlüğü arasında imzalanan protokole dayanmaktadır. Günümüze kadar geçen süreç içerisinde su havzalarıyla ilgili yönetmelikte bölgede yapılaşmayı teşvik eden bazı değişiklikler yapılmıştır. Gelen imar aflarının içerikleri su havzalarındaki yapıları da kapsamıștır. Önlenemeyen kaçak yapılaşma bu bölgelerde Çatalca dışında belediye yok iken, 19851995 yılları arasındaki dönemde yeni belediyelerin oluşmasına neden olmuştur.

\section{SONUÇ}

Günümüz teknolojisi ile elde edilen uydu görüntüleri, özellikle geniş alanların değerlendirilmesinde kullanılabilecek en iyi verilerden birisidir. Uydu görüntülerinin bilgiye dönüştürülebilmesi için bir takım işlemler yapılması gerekmektedir. $\mathrm{Bu}$ işlemlerin sonucunda topografya üzerinde meydana gelen değişiklikler izlenebilmektedir. $\mathrm{Bu}$ çalışmada İstanbul Metropolitan alan içerisindeki Elmalı su havzasındaki arazi kullanım değişiklikleri incelenmiştir. Çalışma sonucunda, sınırlı bir alanda, nüfus ve ekonomik faaliyetlerin bu oranda yoğunlaşması, gerek doğal kaynaklar üzerinde gerekse kentsel alanda sosyal ve çevresel altyapı üzerinde giderek artan baskı oluşturduğu tespit edilmiştir. Aynı zamanda Elmalı su havzası içerisinde bulunan kamu arazilerinin işgal edilmesinde TEM otoyolu, Boğaz Köprüsü ve Dudullu Organize Sanayi Bölgesinin de katkısının olduğu görülmüştür. Havzaların etrafında bulunan büyük iş potansiyeline sahip organize sanayi bölgeleri ve sanayi kuruluşları nüfus artışını ve yerleşimi hızlandırmıştır. Neticede, yaşam kaynağı olan doğal kaynakların üzerindeki yerleşim alanların izlemesinde, arazi kullanım değişiminde, kaçak yapıların tespit edilmesinde, yüksek çözünürlüklü uydu görüntülerinden yararlanılması doğal kaynakların düzenli planlanmasında önemli bir rol oynayacaktır.

\section{TEŞEKKÜR}

$\mathrm{Bu}$ çalışmada veri temini konusunda bizlere yardımc1 olan "Earth Resources Observation and Science (EROS) Center" Uzaktan Algilama merkezine teşekkür ederiz.

\section{KAYNAKLAR}

Akbulak, C., Evren, E.A., Öztürk, B. 2008. Gelibolu Yarımadası'nın Kuzeybatı Kiyılarında Arazi Kullanımının Uzaktan Algılama İle İncelenmesi. Selçuk Üniversitesi Sosyal Bilimler Enstitüsü Dergisi, (20): 42-50.

Anderson, J.R., Hardy, E.E., Roach, J.T., Witmer, R.E. 1976. A Land Use and Land Cover Classification System for Use with Remote Sensor Data. U.S. Geological Survey, Professional Paper 964. Reston, VA.

ArcGIS, 2016. Using ArcGIS Desktop. ESRI Press publishes, Redlands, California.

Balcik, F.B, Goksel C. 2005. Analysing and Mapping of Bozcaada İsland Land Cover by Means of Remote Sensing and GIS Integration. 25th EARSeL Symposium and Workshops, Porto, Portugal. 
Balçık, F.B., Bozkaya, G., Göksel, Ç., Doğru, A.Ö., Uluğtekin, N.N., Sözen, S. 2011. İğneada Arazi Örtüsü Ve Kullanımı Değişiminin Uzaktan Algılama Ve Coğrafi Bilgi Sistemleri İle Belirlenmesi. TMMOB Coğrafi Bilgi Sistemleri Kongresi, 31 Ekim-4 Kasım, Antalya.

Canıberk, M., Kiracı, A.C. 2014. Arazi Kullanımının Zamansal Değişiminin Tarihi Ortofotolarla Belirlenmesi (Elmalı havzası örneği). 5. Uzaktan algilama-CBS sempozyumu (UZAL-CBS 2014), 1417 Ekim, İstanbul.

Congalton, R.G., Green, K. 1998. Assessing the Accuracy of Remotely Sensed Data: Principles and Practices. New York: Lewis Publishers.

Dewan, A. M., Yamaguchi, Y. 2009. Land Use and Land Cover Change in Greater Dhaka, Bangladesh: Using Remote Sensing to Promote. Applied Geography, (29): 390-401.

Geymen A. 2013. Impacts of Bosporus Bridges on the Istanbul Metropolitan Settlement Areas. Land Degradation \& Development, 24(10): 156-169.

Geymen, A., Küçükmehmetoğlu, M., Baz, İ. 2006 İstanbul Metropolitan Alanındaki Hizlı Kentleşmenin $\mathrm{Su}$ Havzalarına Olan Etkilerinin İncelenmesi. 1. Uzaktan Algılama ve CBS Çalıştayı, 27-29 Kasım, İstanbul.

Gülersoy, A.E. 2001. Gömeç Ovası'nda Bugünkü Arazi Kullanımı ile Arazi Sinıflandırılması Arasındaki İlişkiler. Yüksek Lisans Tezi, D.E.Ü. Eğitim Bilimleri Enstitüsü, İzmir, 268s.

Gülersoy, A.E. 2008. Bakırçay Havzası'nda Doğal Ortam Koşulları ile Arazi Kullanımı Arasındaki İlişkiler. Doktora Tezi, D.E.Ü. Eğitim Bilimleri Enstitüsü, İzmir, 494s.

Gülersoy, A.E. 2010. Farklı Uzaktan Algılama Teknikleri Kullanılarak Arazi Örtüsü/Kullanımında Meydana Gelen Değişimlerin İncelenmesi: Manisa Merkez İlçesi Örneği (1986-2010). Turkish Studies International Periodical For The Languages, Literature and History of Turkish or Turkic, 8(8): 1915-1934.

Gürbüz, M., Denizdurduran, M., Karabulut, M., Kizılelma, Y. 2012. Uzaktan Algilama ve CBS Kullanarak Elbistan Ovasinda Arazi Kullanımı/Arazi Örtüsünde Meydana Gelen Değişimlerin İncelenmesi. KSÜ Mühendislik Bilimleri Dergisi, Özel Say1:30-37.

IMP, 2006. Analysis of Drinking and Use Water Resources in the Edition of Preliminary Etude Works for 1/100 000 scaled Strategic Planning.

Kara, F., Karatepe, A . 2012. Uzaktan Algilama Teknolojileri ile Beykoz İlçesi (1986-2011) Arazi Kullanımı Değişim Analizi. Marmara Coğrafya Dergisi, (25): 378-389.
Kaya, Ö., Toroğlu, E. 2015. Monitoring Urban Development of Kayseri and Change Detection Analysis. Türk Coğrafya Dergisi, 65: 87-96.

KTVKK, 1995. T.C. Kültür Bakanlığı İstanbul 3 Numaralı Kültür ve Tabiat Varlıklarını Koruma Kurulu Müdürlüğü, 7755 Sayılı Karar. (http://www.kulturvarliklari.gov.tr)

Liang, S. 2004. Quantitative Remote Sensing of Land Surfaces, John Wiley and Sons, New Jersey, USA.

Liu, Y. 2009. Modeling Urban Development Geographical Information Systems and Celluar Automata. Boca Raton: CRC Press, Taylor \& Francis Group.

Musaoglu, N, Tanik, A, Kocabas, V. 2005. Identification of Land-Cover Changes Through İmage Processing and Associated Impacts on Water Reservoir Conditions. Environmental Management, 35: 220-230.

Öztürk, D., Şişman, A., Erdem, E.M., Şişman, Y. 2010. Detection of Land-use/Land-cover Changes Using Remote Sensing and GIS in Atakum, Samsun. VI. Ulusal Coğrafya Sempozyumu, 3-5 Kasım 2010, Ankara.

Sener, M., Altıntas, B., Kurc, H.C. 2013. Planning and Controlling of Hazelnut Production Areas with the Remote Sensing Techniques. KSÜ Doğa Bil. Derg., 16(1): 16-23.

Shalaby, A., Tateishi, R. 2007. Remote Sensing and GIS for Mapping and Monitoring Land Cover And LandUse Changes in the Northwestern Coastal Zone of Egypt. Applied Geography, (27): 28-41.

TUIK, 2014. Türkiye İstatistik Kurumu Nüfus Sayım Bilgileri, www.tuik.gov.tr/PreTablo.do?alt_id=1059 http://tuikapp.tuik.gov.tr/nufusmenuapp/menu.zul

Topaloğlu, R. H., Ekercin, S. 2013. Coğrafi Bilgi Sistemi ve Uzaktan Algilama Entegrasyonu ile Konya Kapalı Havzası'nda Arazi Örtüsü/Kullanımı Zamansal Değişimlerinin Belirlenmesi. Ankara: TMMOB Coğrafi Bilgi Sitemleri Kongresi, 11-13 Kasim 2013, Ankara.

URL: 2016. http://remotesensing.usgs.gov/about.php, (Erişim tarihi: 12.02.2016).

Wu, Q., Li, H., Wang, R., Paulussen, J., He, Y., Wang, M., Wang, Z. 2005. Monitoring and Predicting Land Use Change in Beijing Using Remote Sensing and GIS. Landscape And Urban Planning, (78): 322-333.

Yıldırım, Ü. ve Kilıç, F., 2006. Uzaktan Algılama Yöntemleri ile Afyonkarahisar'ın Şehirsel Gelişiminin İzlenmesi. Fatih Üniversitesi, 4. Coğrafi Bilgi Sistemleri Bilişim Günleri, 13 - 16 Eylül 2006.

Yılmaz, S., Marangoz, A.M., Şekertekin, A., Oruç, M., Kutoğlu, Ş.H. 2015. Uzaktan Algılama Teknikleri ile Zonguldak İli Kentsel Gelişiminin İzlenmesi ve Alternatif Yerleşim Alanlarının Belirlenmesi. TUFUAB VIII. Teknik Sempozyumu, 21-23 Mayıs 2015, Konya. 